\title{
Improper Flow or Infusion
}

National Cancer Institute

\section{Source}

National Cancer Institute. Improper Flow or Infusion. NCI Thesaurus. Code C63110.

Problem associated with the regulation and delivery of therapeutic agents (e.g. air, gas, drugs or fluids into a device or a patient under positive pressure). 